\title{
Examination of Balance and Isokinetic Strength in Female Volleyball Players
}

\author{
Elif Cengizel $^{1} \&$ Cagdas Ozgur Cengizel $^{2}$ \\ ${ }^{1}$ Department of Trainer Education, Faculty of Sport Sciences, Gazi University, Ankara, Turkey \\ ${ }^{2}$ Institute of Health Sciences, Gazi University, Ankara, Turkey \\ Correspondence: Elif Cengizel, Gazi University, Abant Sok. No: 12, Yenimahalle, 06330 Ankara, Turkey. \\ E-mail: elifoz@gazi.edu.tr
}

Received: August 25, 2019

Accepted: September 30, 2019 Online Published: October 24, 2019

doi:10.5539/jel.v8n6p31

URL: https://doi.org/10.5539/jel.v8n6p31

\begin{abstract}
The purpose of this research is: (a) to compare the dominant and non-dominant leg isokinetic strength and balance, (b) to compare the balance applied on the same side to different directions and isokinetic strength applied to the same side at different angular velocities and (c) to examine the relationship between the balance and isokinetic strength applied at different angular velocities in female volleyball players. Eleven senior female volleyball players voluntarily participated in the research. Isokinetic knee flexion and extension strength were separately obtained on concentric/concentric dominant and non-dominant leg as 5 repetitions at $60^{\circ} . \mathrm{s}^{-1}$ angular velocity, 10 repetitions at $180^{\circ} . \mathrm{s}^{-1}$ and 15 repetitions at $300^{\circ} . \mathrm{s}^{-1}$. The balance test was performed for both sides in anterior (ANT), posterolateral (PL) and posteromedial (PM) directions. In female volleyball players, there is no significant difference between the dominant and non-dominant leg in terms of isokinetic strength and balance. A significant difference was detected between the balance applied in different directions on the same side and isokinetic force applied at different angular velocities. However, there is not any significant relationship between isokinetic strength and balance in female volleyball players. As a result, there is no isokinetic strength and balance asymmetry in volleyball and there is no relationship between them. This may be an indication of the need for both legs in volleyball.
\end{abstract}

Keywords: volleyball, balance, isokinetic strength, dominant leg, muscle strength

\section{Introduction}

Today, volleyball is a popular sports branch with high participation especially in females. Following the technical development in recent years, volleyball has become a high-pace game played especially by female volleyball players. Volleyball is a team sport that hosts explosive power elements such as jump, spike and block. In addition to these technical elements, one of the most important factors affecting the success of elite athletes in competitions is muscle strength (Marques, van den Tillaar, Vescovi, \& Gonzalez-Badillo, 2008). Sports which involve maximal strength like jump require a high level of motor characteristics of hamstring and quadriceps (Kim \& Jeoung, 2016; Magalhaes, Oliveira, Ascensao, \& Soares, 2004).

In this context, particularly volleyball involves movements requiring different muscle strength at fast or slow tempo. The performance of a volleyball player is directly affected by this power production capacity (Schons, Fischer, Rosa, Berriel, \& Peyré-Tartaruga, 2018). In addition, muscle strength is an indispensable part of sportive performance (Lidor \& Ziv, 2010). The balance between the dominant and non-dominant leg muscle strength in volleyball — despite the minimal differences between them — is very important (Kim \& Jeoung, 2016). Eccentric and concentric muscle activation throughout the game is often observed in technical elements (such as spike, block) applied in volleyball. For example, for a strong spike, the explosive force of the lower extremities and back muscles is used and this requires whole body control to prevent injuries (Kim \& Jeoung, 2016).

Muscle strength is an important component in sports in terms of exhibiting high performance and preventing injury. Isokinetic tests are among the most commonly used methods to determine knee muscle strength. The most frequently examined parameters in these tests are the dominant and non-dominant strength and agonist-antagonist strength balance (Magalhaes et al., 2004). Isokinetic dynamometer devices that are used to determine muscle strength are reliable and valid methods (Dekerle, Barstow, Regan, \& Carter, 2014; Hadzic, 
Sattler, Markovic, Veselko, \& Dervisevic, 2010). Isokinetic dynamometer tests provide data regarding the parameters such as strength, torque and power at different velocities (Cronin \& Hansen, 2005). These data are used to measure the torques of different joints (Kim \& Jeoung, 2016).

In volleyball, balance is necessary for a good stabilization in the phases of spike and block jumps, approach and landing (Pau, Loi, \& Pezzotta, 2012; Wagner, Tilp, \& Mueller, 2009). Inadequate balance in athletes is a risk factor in terms of lower extremity injuries (Trojian \& McKeag, 2006). Balance plays a critical role not only in daily life activities but also in sports competitions. While sport activities change body control, the body balance needs to be protected in the effective practice of technical elements (Chander \& Dabbs, 2016). In addition, balance is affected by many factors such as information coming from sensory system, joint range of motion and joint strength. These motions help to prevent sports-related injuries in complex technical components (Palmieri, Ingersoll, Stone, \& Krause, 2002).

Dynamic balance is described as "the ability to execute a movement while keeping a stable position of the body" (Winter, Patla, \& Frank, 1990). Balance and balance training are essential for sportive performance. Balance performance of female players in different sports branches can be observed during the season to prevent injuries that can occur due to loss of balance (Chander \& Dabbs, 2016). The number of the studies examining the balance performance in female volleyball players is very low (Hudson, Garrison, \& Pollard, 2016; Pau et al., 2012; Şahin et al., 2015).

The low number of researches is attention-grabbing although female volleyball players significantly need quadriceps \& hamstring muscle strength in jump performance (Pupo, Detanico, \& dos Santos, 2012). Lower extremity strength imbalances can create negative effect in terms of jumps in volleyball (Schons, Da Rosa et al., 2018). Muscle imbalance is one of the internal factors mostly mentioned in sports injuries. At this point, muscle strength assessments gain importance in order to prevent sports injuries (Magalhaes et al., 2004). Furthermore, the existence of bilateral differences between the dominant and the non-dominant leg still remains controversial. Accordingly, the purpose of this research is: (a) to compare the dominant and non-dominant leg isokinetic strength and balance, (b) to compare the balance applied on the same side to different directions and isokinetic strength applied to the same side at different angular velocities and (c) to examine the relationship between the balance and isokinetic strength applied at different angular velocities in female volleyball players.

\section{Method}

\subsection{Subjects}

11 senior female volleyball players were voluntarily participated in this study (Table 1). All athletes provided written informed consent prior to their enrollment in the study. Before the measurements began, the athletes underwent one month of pre-season training. The measurements were taken at the beginning of the competition season. All players were informed about the test design and potential risks.

Table 1. Characteristics of the subjects

\begin{tabular}{ll}
\hline & Mean \pm SD \\
\hline Age (year) & $20.2 \pm 3.9$ \\
Years of experience (year) & $11.0 \pm 4.2$ \\
Body height $(\mathrm{cm})$ & $176.8 \pm 7.1$ \\
Body weight $(\mathrm{kg})$ & $66.6 \pm 5.7$ \\
Fat percentage $(\%)$ & $20.5 \pm 3.9$ \\
\hline
\end{tabular}

\subsection{Study Design}

Before performing the balance and isokinetic tests, the dominant legs of the subjects were determined (the left leg was dominant in 10 subjects, the right leg was dominant in 1 subject). The players completed a standard warm-up protocol for 30 minutes before starting the test (Line drills \& dynamic stretching, respectively).

The measurements were taken on four separate days. The physical characteristics and balance were measured on the first day. On the other days, dominant and non-dominant side isokinetic knee flexion \& extension strength were measured as concentric/concentric contraction on the second day at $60^{\circ} . \mathrm{s}^{-1}$ angular velocity as 5 repetitions, on the third day at $180^{\circ} . \mathrm{s}^{-1}$ angular velocity as 10 repetitions and on the fourth day at $300^{\circ} . \mathrm{s}^{-1}$ angular velocity as 15 repetitions, respectively.

Y-balance test was used to determine the balance performance of the subjects. Measurements were taken in 3 
different directions of anterior (ANT), posteromedial (PM) and posterolateral (PL) on both the dominant and non-dominant legs for both sides. Subjects were allowed at least 3 practice trials in the ANT, PM and PL directions prior to recording the best of 3 formal trials in each plane. Three trials were completed on the dominant leg in the ANT direction followed by 3 trials completed on the non-dominant leg. This protocol was then performed in the PM and PL directions. The maximal reach distance was recorded at the place where the most distal part of the foot reached.

Isokinetic testing was performed to determine concentric strength for the knee-extensors and flexors using IsoMed 2000 isokinetic dynamometer (D.\&R. Ferstl GmbH, Hemau, Germany). The subjects were tested in a seated position. The subjects were fastened to the isokinetic dynamometer with belts from their bodies, hips and legs. Each subject performed knee flexion and extension with 3 sub-maximal and 1 maximal repetition to understand the resistance of the device. When the exercise was completed on one side, the subject was given 3-minute rest (Hadzic et al., 2010; Sattler, Sekulic, Esco, Mahmutovic, \& Hadzic, 2015). During the tests, the players were encouraged verbally.

\subsection{Data Analysis}

Sigma Plot 11.0 (Systat Software, Inc) was used to evaluate the descriptive statistics. In the analysis of the data, (a) paired t-test (Wilcoxon) was used in the comparison of the balance and isokinetic strength of the dominant and non-dominant legs (b) Holm-Sidak was used in the comparison of the same side balance and isokinetic strength and (c) Spearman correlation test was used for the relationship between balance and isokinetic strength applied at different angular velocities $(\mathrm{p}<0.05)$.

\section{Results}

The dominant leg balance was found to be quantitatively higher than the non-dominant leg balance in elite female volleyball players. At all angular velocities, Q (extension) muscle strength was found to be higher than $\mathrm{H}$ (flexion) muscle strength on both sides. In addition, the highest peak torque value on the dominant and non-dominant legs was obtained at $60^{\circ} . \mathrm{s}^{-1}$ velocity (compared to $180^{\circ} . \mathrm{s}^{-1}$ and $300^{\circ} . \mathrm{s}^{-1}$ velocities). The isokinetic strength and balance of the subjects were not significantly different between the dominant and non-dominant legs (Table 2).

Table 2. Comparison of dominant and non-dominant leg isokinetic strength (con-con) and balance in female volleyball players

\begin{tabular}{lllll}
\hline & & Dominant leg & Non-dominant leg & $\mathrm{p}$ \\
\hline Balance & ANT $(\mathrm{cm})$ & $90.5 \pm 7.5$ & $90.1 \pm 6.2$ & 0.645 \\
& PL $(\mathrm{cm})$ & $95.9 \pm 6.9$ & $100.2 \pm 7.0$ & 0.129 \\
& PM $(\mathrm{cm})$ & $93.5 \pm 8.5$ & $95.5 \pm 9.0$ & 0.375 \\
Isokinetic strength & $60^{\circ} . \mathrm{s}^{-1}$ flexion $(\mathrm{H})(\mathrm{Nm})$ & $89.4 \pm 13.5$ & $89.0 \pm 13.7$ & 0.767 \\
& $60^{\circ} . \mathrm{s}^{-1}$ extension $(\mathrm{Q})(\mathrm{Nm})$ & $142.6 \pm 22.3$ & $147.0 \pm 23.3$ & 0.818 \\
& $180^{\circ} . \mathrm{s}^{-1}$ flexion $(\mathrm{H})(\mathrm{Nm})$ & $76.7 \pm 9.6$ & $76.0 \pm 9.5$ & 0.554 \\
& $180^{\circ} . \mathrm{s}^{-1}$ extension $(\mathrm{Q})(\mathrm{Nm})$ & $103.0 \pm 13.0$ & $103.1 \pm 11.8$ & 0.895 \\
& $300^{\circ} . \mathrm{s}^{-1}$ flexion $(\mathrm{H})(\mathrm{Nm})$ & $65.9 \pm 13.4$ & $65.4 \pm 11.8$ & 0.999 \\
& $300^{\circ} . \mathrm{s}^{-1}$ extension $(\mathrm{Q})(\mathrm{Nm})$ & $88.1 \pm 14.4$ & $85.3 \pm 10.8$ & 0.646 \\
\hline
\end{tabular}

Note. H: Hamstrings, Q: Quadriceps, ANT: Anterior, PL: Posterolateral, PM: Posteromedial.

The isokinetic strength applied on the same side at different angular velocities (e.g., Q (extension) muscle strength comparison at $60^{\circ} . \mathrm{s}^{-1}, 180^{\circ} . \mathrm{s}^{-1}, 300^{\circ} . \mathrm{s}^{-1}$ velocities on the non-dominant leg) are significantly different in all parameters (Table 3 ).

Table 3. Comparison of isokinetic strength for the same side at different angular velocities in female volleyball players

\begin{tabular}{|c|c|c|c|c|c|c|c|}
\hline & & \multicolumn{3}{|c|}{ Hamstring } & \multicolumn{3}{|c|}{ Quadriceps } \\
\hline & & $60^{\circ} \cdot \mathrm{s}^{-1}$ & $180^{\circ} \cdot \mathrm{s}^{-1}$ & $300^{\circ} \cdot \mathrm{s}^{-1}$ & $60^{\circ} . \mathrm{s}^{-1}$ & $180^{\circ} \cdot \mathrm{s}^{-1}$ & $300^{\circ} . \mathrm{s}^{-1}$ \\
\hline \multirow[t]{3}{*}{ Non-dominant } & $60^{\circ} \cdot \mathrm{s}^{-1}$ & - & $<0.001$ & $<0.001$ & - & $<0.001$ & $<0.001$ \\
\hline & $180^{\circ} . \mathrm{s}^{-1}$ & $<0.001$ & - & 0.002 & $<0.001$ & - & 0.004 \\
\hline & $300^{\circ} \cdot \mathrm{s}^{-1}$ & $<0.001$ & 0.002 & - & $<0.001$ & 0.004 & - \\
\hline \multirow[t]{2}{*}{ Dominant } & $60^{\circ} \cdot \mathrm{s}^{-1}$ & - & $<0.001$ & $<0.001$ & - & $<0.001$ & $<0.001$ \\
\hline & $180^{\circ} \cdot \mathrm{s}^{-1}$ & $<0.001$ & - & $<0.001$ & $<0.001$ & - & $<0.001$ \\
\hline
\end{tabular}


In terms of the balance applied on the same side to different directions, there is a significant difference between the dominant \& non-dominant leg ANT and PL balance (dominant leg ANT vs PL balance $p<0.001$, non-dominant leg ANT vs PL balance $p=0.007)$ and also between the dominant side ANT and PM balance (dominant leg ANT vs PM balance $\mathrm{p}=0.038$ ) (Table 4).

Table 4. Comparison of balance applied to different directions for female volleyball players for the same side

\begin{tabular}{|c|c|c|c|c|c|c|}
\hline & \multicolumn{3}{|c|}{ Non-dominant } & \multicolumn{3}{|l|}{ Dominant } \\
\hline & ANT & PL & $\mathrm{PM}$ & ANT & PL & $\mathrm{PM}$ \\
\hline ANT & - & $0.007^{*}$ & 0.120 & - & $<0.001^{*}$ & $0.038^{*}$ \\
\hline PL & $0.007^{*}$ & - & 0.185 & $<0.001^{*}$ & - & 0.064 \\
\hline $\mathrm{PM}$ & 0.120 & 0.185 & - & $0.038^{*}$ & 0.064 & - \\
\hline
\end{tabular}

No significant relationship was determined between balance and isokinetic strength applied at different angular velocities (Table 5, except for non-dominant leg $300^{\circ} . \mathrm{s}^{-1}$ flexion strength $(\mathrm{H})$ and PM balance, $\mathrm{r}=0.615, \mathrm{p}=$ 0.039).

Table 5. Examination of the relationship between isokinetic force and balance applied by female volleyball players at different angular velocities

\begin{tabular}{|c|c|c|c|c|c|c|c|c|c|c|c|c|}
\hline & \multicolumn{6}{|c|}{ Non-dominant } & \multicolumn{6}{|c|}{ Dominant } \\
\hline & \multicolumn{2}{|c|}{ ANT } & \multicolumn{2}{|l|}{ PL } & \multicolumn{2}{|l|}{$\mathrm{PM}$} & \multicolumn{2}{|c|}{ ANT } & \multicolumn{2}{|l|}{ PL } & \multicolumn{2}{|l|}{$\mathrm{PM}$} \\
\hline & $\mathrm{r}$ & $\mathrm{p}$ & $\mathrm{r}$ & $\mathrm{p}$ & $\mathrm{r}$ & $\mathrm{p}$ & $\mathrm{r}$ & $\mathrm{p}$ & $\mathrm{r}$ & $\mathrm{p}$ & $\mathrm{r}$ & $\mathrm{p}$ \\
\hline $60^{\circ} . \mathrm{s}^{-1}(\mathrm{H})$ & .243 & .450 & .476 & .132 & .580 & .055 & .110 & .734 & .0 .37 & .903 & .282 & .384 \\
\hline $60^{\circ} \cdot \mathrm{s}^{-1}(\mathrm{Q})$ & .165 & .614 & .557 & .070 & .565 & .065 & -.096 & .755 & -.0 .04 & .881 & .214 & .502 \\
\hline $180^{\circ} \cdot \mathrm{s}^{-1}(\mathrm{H})$ & .439 & .168 & .347 & .283 & .419 & .188 & .250 & .450 & -.022 & .484 & .055 & .860 \\
\hline $180^{\circ} \cdot \mathrm{s}^{-1}(\mathrm{Q})$ & .151 & .633 & .539 & .082 & .465 & .141 & -.0 .21 & .946 & -.202 & .538 & .069 & .818 \\
\hline $300^{\circ} \cdot \mathrm{s}^{-1}(\mathrm{H})$ & .339 & .296 & .247 & .450 & .615 & $.039 *$ & . -087 & .776 &.-339 & .296 & .032 & .903 \\
\hline $300^{\circ} \cdot \mathrm{s}^{-1}(\mathrm{Q})$ & .222 & .502 & .364 & .257 & .121 & .714 & .009 & .968 & -413 & .199 & -223 & .484 \\
\hline
\end{tabular}

Note. *: $\mathrm{p}<.05$, ANT: Anterior, PL: Posterolateral, PM: Posteromedial.

\section{Discussion and Conclusion}

In the literature, it is possible to come across the researches in which the isokinetic knee strength of different sports branches and volleyball players was determined (Cheung, Smith, \& Wong, 2012; Kabaciński et al., 2017). In these researches, the focus was mostly on the H/Q ratio. However, there are also studies where the effect of different training programs on isokinetic strength and balance in volleyball players was examined (Mohammadi, Alizadeh, \& Gaieni, 2012; Myer, Ford, Brent, \& Hewett, 2006; Pau et al., 2012; Şahin et al., 2015; Yong-Youn $\&$ Si-Eun, 2016). Gender makes the strength differences apparent especially in the senior category. The point attracting attention is that the number of the research conducted on isokinetic knee strength in males is considerably high (Bamaç et al., 2008; Çelenk, Öz, Öner, \& Öz, 2019; Cheung et al., 2012; Hadzic et al., 2010; Kim \& Jeoung, 2016; Markou \& Vagenas, 2006; Özkan \& Kİn-İşler, 2011; Schons, Da Rosa et al., 2018).

The selected studies choose different execution speeds in the isokinetic dynamometry test. The speeds used in isokinetic dynamometry assessments with volleyball players range from low angular speeds $\left(30\right.$ and $\left.60^{\circ} . \mathrm{s}^{-1}\right)$, allowing for greater torque production, up to higher angular speeds, such as $300^{\circ} . \mathrm{s}^{-1}$, in order to be closer to the speed of muscle contraction performed by knee joint muscles in sports practice (D'Alessandro, Silveira, Anjos, Silva, \& Fonseca, 2005). In our research, we determined three different angular velocities as low- $60^{\circ} . \mathrm{s}^{-1}$, moderate- $180^{\circ} . \mathrm{s}^{-1}$ and high $-300^{\circ} . \mathrm{s}^{-1}$ to detect isokinetic knee strength in female volleyball players.

Knee extensor muscles are active at the maximum level during spike in the phases of landing and take-off (Hadzic et al., 2010). In young male volleyball players, a significant relationship was found between the isokinetic strength at low angular velocity and vertical jump. In addition, it was suggested to give importance to leg strength trainings in order to increase the jump performance of volleyball players (Çelenk et al., 2019). This situation indicates the importance of knee extensors on technical elements in volleyball.

Muscle strength asymmetry associated with sportive technical elements may be observed in the players subjected to intensive weekly training. Muscle imbalance from one limb to another, called contralateral deficit. If 
contralateral deficit is higher than $15 \%$, there is a risk of injury (Croisier, Ganteaume, Binet, Genty, \& Ferret, 2008). As a result of their research, Croisier et al. (2008) suggested that isokinetic intervention gives rise to the pre-season detection of strength imbalances, a factor that increases the risk of a hamstring injury.

Muscle imbalance may be an indicator of some potential injury risks like soft tissue injury (Zakas, Mandroukas, Vamvakoudis, Christoulas, \& Aggelopoulou, 1995). In the literature, it is stated that the increasing hamstring activation during knee extension decreases excessive tension in anterior cruciate ligament (ACL), hamstrings stabilize the knee by supporting ACL by preventing the tibia from sliding in front of the femur, and hamstring muscle strength and ACL support each other (Pettitt \& Bryson, 2002; Tourny-Chollet \& Leroy, 2002). When the quadriceps generate substantially larger forces as compared to the hamstrings, excessive anterior translation may occur during dynamic activities, and the ACL will experience higher-than-normal shear forces. If the hamstrings are too weak to counteract this force, the ACL may be injured (Cheung et al., 2012).

We think that there may be strength asymmetry in the athletes performing unilateral training for a long time. Strength asymmetry can be observed especially in the sports branches that perform jumping on one leg. In volleyball, when the player starts the take-off phase (except for single leg hop), he pushes himself off the ground at the same time. In our research, not determining the strength asymmetry in female volleyball players can be explained by the movement pattern specific to this technique.

Markou and Vagenas (2006) detected upper limb and lower limb asymmetry in male offensive volleyball players and emphasized that this situation needed to be taken into account in the training and rehabilitation of athletes. It should be considered that they used the knee isokinetic strength only at $60^{\circ} . \mathrm{s}^{-1}$ angular velocity, the experimental group consisted of only male athletes and the year when the research was conducted. Especially the diversity of the trainings performed in today's volleyball and differentiation of the playing velocity may have taken a role in this result. Hadzic et al. (2010) measured the concentric and eccentric knee muscle strength in male volleyball players at $60^{\circ} . \mathrm{s}^{-1}$ angular velocity. In contrary to Markou and Vagenas (2006), they did not detect any bilateral strength asymmetry in their research. They also noted that these results strongly suggest that volleyball does not produce abnormal bilateral asymmetry in knee extensor and flexor muscles, at least not in men. In another research, isokinetic knee strength was examined at $60^{\circ} . \mathrm{s}^{-1}$ and $180^{\circ} . \mathrm{s}^{-1}$ velocities in male athletes engaged in different team sports and no bilateral asymmetry was observed in the volleyball players (Teixeira, Carvalho, Moreira, \& Santos, 2014). In our research, we did not detect any bilateral strength asymmetry in elite female volleyball players. Whether there is a bilateral strength asymmetry especially in female volleyball players should be analyzed in depth in future studies.

Most of the studies examining the isokinetic knee strength in volleyball are on male athletes. Therefore, it is not appropriate to compare the data obtained in these studies with the findings of our research due to gender difference. One of the researches, where the isokinetic strength was measured in a limited number of female volleyball players, is in the youth category. Akınoğlu, Kocahan, Özsoy, Hamamcilar, and Hasanoğlu (2019) evaluated the $60^{\circ} . \mathrm{s}^{-1}$ and $180^{\circ} . \mathrm{s}^{-1}$ knee flexion and extension isokinetic strength in young female and male volleyball players (mean age: females $n=9,15.67 \pm 0.70$ years, males $n=9,16.00 \pm 0.55$ years). In the research, it was determined that there was a statistically significant difference between the peak torque of the flexor and extensor muscles of the dominant side knee joint and that female athletes were weaker than male athletes $(\mathrm{p}<$ 0.05). In this research, a comparison was not made between the dominant and non-dominant side, but the agonist-antagonist muscle strength as well as the gender comparison were made. On the other hand, the knee isokinetic peak torque values of female volleyball players show minimal differences with our findings.

The Y-balance test was utilized as a measure of trunk and lower extremity function. Y-balance test is one of the tests which is widely and easily used to measure the balance performance of athletes in athletic performance laboratories. It was reported that the balance and strength of the athletes increased with balance trainings (Heitkamp, Horstmann, Mayer, Weller, \& Dickhuth, 2001; Lee \& Han, 2016).

In a research conducted on tennis players, it was reported that balance trainings reduced the lower extremity strength asymmetry (Sannicandro, Cofano, Rosa, \& Piccinno, 2014). In young male athletes, an increase was observed in the balance performance in ANT, PL and PM directions after 6-week strength training. Researchers suggest that the increase in lower extremity strength can lead to an increase in dynamic and static balance and postural control (Mohammadi et al., 2012). Suveren Erdoğan et al. (2016) reported that balance exercises increased lower extremity muscle stabilization in male volleyball players.

Hudson, Garrison and Pollard (2016) compared the balance performance of ninety elite female volleyball players between the dominant and non-dominant sides according to different directions. Y-balance test was used in the determination of the balance performance. At the end of the study, there were no significant balance differences 
in dominant and non-dominant legs between directions. This result coincides with our research findings.

No significant relationship was found between the isometric muscle strength and balance in healthy males, and it was reported that these capacities may be independent of each other and may need to be tested and trained (Muehlbauer, Gollhofer, \& Granacher, 2013).

The present study has certain limitations that need to be weighted. Although the subject group consists of elite volleyball players, the sample group is limited. Moreover, we focused on only peak torque from the isokinetic parameters. On the other hand, our research is important in terms of measuring isokinetic knee strength at three different angular velocities and studying on female volleyball players. Furthermore, examining the relationship between isokinetic knee strength and balance at different angular velocities is one of the strengths of our research.

In volleyball, coaches and team conditioners can program the balance and isokinetic strength trainings of athletes in line with the above-mentioned information. In this way, they can improve the performance of athletes or compare these data with the data of the athletes. As a result, there is no significant difference between the dominant and non-dominant leg in terms of isokinetic strength and balance in female volleyball players. A significant difference was detected between the balance applied in different directions on the same side and isokinetic force applied at different angular velocities. However, there is not any significant relationship between isokinetic strength and balance in female volleyball players. While there is no isokinetic strength and balance asymmetry in volleyball, there is also no relationship between them. This may be an indication of the need for both legs in volleyball. It may be suggested to conduct similar studies also in males and in different age categories.

\section{Acknowledgements}

This study was presented as oral presentation at the 2nd International Conference on Sports for All and Wellness in 2019.

\section{References}

Akınoğlu, B., Kocahan, T., Özsoy, H., Hamamcılar, O., \& Hasanoğlu, A. (2019). Comparison of the knee joint muscle strength and muscle strength balance in female and male volleyball players. Turkiye Klinikleri Journal of Sports Sciences, 11(2), 67-73. https://doi.org/10.5336/sportsci.2019-66584

Bamaç, B., Çolak, T., Özbek, A., Çolak, S., Cinel, Y., \& Yenigün, Ö. (2008). Isokinetic performance in elite volleyball and basketball players. Kinesiology, 40(2), 182-188.

Çelenk, B., Öz, E., Öner, A. G., \& Öz, E. (2019). The relationship between isokinetic knee strength and jumping in young male volleyball players. Turkish Journal of Sport and Exercise, 21(1), 12-15. https://doi.org/10.15314/tsed.521569

Chander, H., \& Dabbs, N. C. (2016). Balance performance and training among female athletes. Strength and Conditioning Journal, 38(2), 8-13. https://doi.org/10.1519/SSC.0000000000000204

Cheung, R., Smith, A., \& Wong, D. (2012). H:Q ratios and bilateral leg strength in college field and court sports players. Journal of Human Kinetics, 33(1), 63-71. https://doi.org/10.2478/v10078-012-0045-1

Croisier, J.-L., Ganteaume, S., Binet, J., Genty, M., \& Ferret, J.-M. (2008). Strength imbalances and prevention of hamstring injury in professional soccer players: A prospective study. The American Journal of Sports Medicine, 36(8), 1469-1475. https://doi.org/10.1177/0363546508316764

Cronin, J. B., \& Hansen, K. T. (2005). Strength and power predictors of sports speed. Journal of Strength and Conditioning Research, 19(2), 349-357. https://doi.org/10.1519/14323.1

D’Alessandro, R. L., Silveira, E. A. P., Anjos, M. T. S. dos, Silva, A. A. da, \& Fonseca, S. T. da. (2005). Analysis on the association between isokinetic dynamometry of the knee's articulation and one-leg horizontal jump, hop test, in volleyball athletes. Revista Brasileira de Medicina Do Esporte, 11(5), 271-275. https://doi.org/10.1590/S1517-86922005000500005

Dekerle, J., Barstow, T. J., Regan, L., \& Carter, H. (2014). The critical power concept in all-out isokinetic exercise. Journal of Science and Medicine in Sport, 17(6), 640-644. https://doi.org/10.1016/j.jsams.2013.09.003

Hadzic, V., Sattler, T., Markovic, G., Veselko, M., \& Dervisevic, E. (2010). The isokinetic strength profile of quadriceps and hamstrings in elite volleyball players. Isokinetics and Exercise Science, 18(1), 31-37. https://doi.org/10.3233/IES-2010-0365 
Heitkamp, H. C., Horstmann, T., Mayer, F., Weller, J., \& Dickhuth, H. H. (2001). Gain in strength and muscular balance after balance training. International Journal of Sports Medicine, 22(4), 285-290. https://doi.org/10.1055/s-2001-13819

Hudson, C., Garrison, J. C., \& Pollard, K. (2016). Y-balance normative data for female collegiate volleyball players. Physical Therapy in Sport, 22, 61-65. https://doi.org/10.1016/j.ptsp.2016.05.009

Kabaciński, J., Murawa, M., Fryzowicz, A., \& Dworak, L. B. (2017). A comparison of isokinetic knee strength and power output ratios between female basketball and volleyball players. Human Movement, 18(3), 40-45. https://doi.org/10.1515/humo-2017-0022

Kim, C.-G., \& Jeoung, B. J. (2016). Assessment of isokinetic muscle function in Korea male volleyball athletes. Journal of Exercise Rehabilitation, 12(5), 429-437. https://doi.org/10.12965/jer.1632710.355

Lee, M., \& Han, G. (2016). The effect of peculiar complex core balance training on isokinetic muscle functions of the knee and lumbus. Journal of Physical Therapy Science, 28(4), 1294-1297. https://doi.org/10.1589/jpts.28.1294

Lidor, R., \& Ziv, G. (2010). Physical and physiological attributes of female volleyball players-A review. Journal of Strength and Conditioning Research, 24(7), 1963-1973. https://doi.org/10.1519/JSC.0b013e3181ddf835

Magalhaes, J., Oliveira, J., Ascensao, A., \& Soares, J. (2004). Concentric quadriceps and hamstrings isokinetic strength in volleyball and soccer players. Journal of Sports Medicine and Physical Fitness, 44(2), 119-125.

Markou, S., \& Vagenas, G. (2006). Multivariate isokinetic asymmetry of the knee and shoulder in elite volleyball players. European Journal of Sport Science, 6(1), 71-80. https://doi.org/10.1080/17461390500533147

Marques, M. C., van den Tillaar, R., Vescovi, J. D., \& Gonzalez-Badillo, J.-J. (2008). Changes in strength and power performance in elite senior female professional volleyball players during the in-season: A case study. Journal of Strength and Conditioning Research, 22(4), 1147-1155. https://doi.org/10.1519/JSC.0b013e31816a42d0

Mohammadi, V., Alizadeh, M., \& Gaieni, A. (2012). The effects of six weeks strength exercises on static and dynamic balance of young male athletes. Procedia - Social and Behavioral Sciences, 31, 247-250. https://doi.org/10.1016/j.sbspro.2011.12.050

Muehlbauer, T., Gollhofer, A., \& Granacher, U. (2013). Association of balance, strength, and power measures in young adults. Journal of Strength and Conditioning Research, 27(3), 582-589. https://doi.org/10.1097/JSC.0b013e31825c2bab

Myer, G. D., Ford, K. R., Brent, J. L., \& Hewett, T. E. (2006). The effects of plyometric vs. dynamic stabilization and balance training on power, balance, and landing force in female athletes. Journal of Strength and Conditioning Research, 20(2), 345-353. https://doi.org/10.1519/R-17955.1

Özkan, A., \& Kİn-İşler, A. (2011). The association among leg volume, leg mass and H/Q ratio with anaerobic performance and isokinetic knee strength in athletes. Hacettepe Journal of Sport Sciences, 21(3), 90-102.

Palmieri, R. M., Ingersoll, C. D., Stone, M. B., \& Krause, B. A. (2002). Center-of-pressure parameters used in the assessment of postural control. Journal of Sports and Rehabilitation, 11, 51-66. https://doi.org/10.1123/jsr.11.1.51

Pau, M., Loi, A., \& Pezzotta, M. C. (2012). Does sensorimotor training improve the static balance of young volleyball players? Sports Biomechanics, 11(1), 97-107. https://doi.org/10.1080/14763141.2011.637126

Pettitt, R. W., \& Bryson, E. R. (2002). Training for women's basketball: A biomechanical emphasis for preventing anterior cruciate ligament injury. Strength and Conditioning Journal, 24(5), 20-29. https://doi.org/10.1519/1533-4295(2002)024<0020:TFWBAB >2.0.CO;2

Pupo, J. D., Detanico, D., \& dos Santos, S. G. (2012). Kinetic parameters as determinants of vertical jump performance. Brazilian Journal of Kinanthropometry and Human Performance, 14(1), 41-51. https://doi.org/http://dx.doi.org/10.5007/1980-0037.2012v14n1p41

Şahin, N., Bianco, A., Patti, A., Paoli, A., Palma, A., \& Ersöz, G. (2015). Evaluation of knee joint proprioception and balance of young female volleyball players: A pilot study. Journal of Physical Therapy Science, 27(2), 437-440. https://doi.org/10.1589/jpts.27.437

Sannicandro, I., Cofano, G., Rosa, R. A., \& Piccinno, A. (2014). Balance training exercises decrease lower-limb 
strength asymmetry in young tennis players. Journal of Sports Science and Medicine, 13(January), 397402 .

Sattler, T., Sekulic, D., Esco, M. R., Mahmutovic, I., \& Hadzic, V. (2015). Analysis of the association between isokinetic knee strength with offensive and defensive jumping capacity in high-level female volleyball athletes. Journal of Science and Medicine in Sport, 18(5), 613-618. https://doi.org/10.1016/j.jsams.2014.08.002

Schons, P., Da Rosa, R. G., Fischer, G., Berriel, G. P., Fritsch, C. G., Nakamura, F. Y., ... Peyré-Tartaruga, L. A. (2018). The relationship between strength asymmetries and jumping performance in professional volleyball players. Sports Biomechanics, 3141, 1-12. https://doi.org/10.1080/14763141.2018.1435712

Schons, P., Fischer, G., Rosa, R. G. da, Berriel, G. P., \& Peyré-Tartaruga, L. A. (2018). Correlations between the strength of knee extensor and flexor muscles and jump performance in volleyball players: A review. Journal of Physical Education, 29(1), 1-12. https://doi.org/10.4025/jphyseduc.v29i1.2926

Suveren Erdoğan, C., Er, F., İpekoğlu, G., Çolakoğlu, T., Zorba, E., \& Çolakoğlu, F. F. (2016). The effects of different type balance exercises on static and dynamic balance performance in volleyball players. Journal of Sports and Performance Researches, 8(1), 11-18.

Teixeira, J., Carvalho, P., Moreira, C., \& Santos, R. (2014). Isokinetic assessment of muscle imbalances and bilateral differences between knee extensores and flexores' strength in basketball, footbal, handball and volleyball athletes. International Journal of Sports Science, 4(1), 1-6. https://doi.org/10.5923/j.sports.20140401.01

Tourny-Chollet, C., \& Leroy, D. (2002). Conventional vs. dynamic hamstring-quadriceps strength ratios: A comparison between players and sedentary subjects. Isokinetics and Exercise Science, 10(4), $183-192$. https://doi.org/10.3233/IES-2002-0102

Trojian, T. H., \& McKeag, D. B. (2006). Single leg balance test to identify risk of ankle sprains. British Journal of Sports Medicine, 40(7), 610-613. https://doi.org/10.1136/bjsm.2005.024356

Wagner, H., Tilp, M., \& Mueller, E. (2009). Kinematic analysis of volleyball spike jump. Orthopedics \& Biomechanics, 30, 760-765. https://doi.org/10.1055/s-0029-1224177

Winter, D. A., Patla, A. E., \& Frank, J. S. (1990). Assessment of balance control in humans. Medical Progress through Technology, 16(1-2), 31-51.

Yong-Youn, K. I. M., \& Si-Eun, P. (2016). Comparison of whole-body vibration exercise and plyometric exercise to improve isokinetic muscular strength, jumping performance and balance of female volleyball players. Journal of Physical Therapy Science, 28(11), 3140-3144. https://doi.org/10.1589/jpts.28.3140

Zakas, A., Mandroukas, K., Vamvakoudis, E., Christoulas, K., \& Aggelopoulou, N. (1995). Peak torque of quadriceps and hamstring muscles in basketball and soccer players of different divisions. Journal of Sports Medicine and Physical Fitness, 35(3), 199-205.

\section{Copyrights}

Copyright for this article is retained by the author, with first publication rights granted to the journal.

This is an open-access article distributed under the terms and conditions of the Creative Commons Attribution license (http://creativecommons.org/licenses/by/4.0/). 